\title{
The adverse effects of virgin microplastics on the fertilization and larval development of sea urchins
}

\author{
Concepción Martínez-Gómez ${ }^{\mathrm{a}, ~}{ }^{*}$, Víctor M. León ${ }^{\mathrm{a}}$, Susana Calles ${ }^{\mathrm{a}}$, \\ Marina Gomáriz-Olcina ${ }^{\mathrm{a}}$, A. Dick Vethaak ${ }^{\mathrm{b}, \mathrm{c}}$ \\ a Instituto Español de Oceanografia (IEO), Oceanographic Centre of Murcia, 30740, San Pedro del Pinatar, Murcia, Spain \\ b Department Environment and Health, VU University, De Boelelaan 1085, 1081 HV, Amsterdam, The Netherlands \\ ${ }^{\mathrm{c}}$ Deltares, Marine and Coastal Systems, PO Box 177, 2600 MH, Delft, The Netherlands
}

\section{A R T I C L E I N F O}

\section{Article history:}

Received 14 December 2016

Received in revised form

8 May 2017

Accepted 26 June 2017

Available online 30 June 2017

\section{Introduction}

The accumulation and fragmentation of plastic debris in marine environments have become a global issue and a growing concern (GESAMP, 2015; Galloway and Lewis, 2016). Plastic debris can be regarded as a complex cocktail of contaminants, including chemical additives, residual monomers and ambient chemical substances sorbed on a polymer (Mato et al., 2001; GESAMP, 2015). Although the impact of larger plastic items, such as plastics bags, fishing nets and plastic fragments, on birds, turtles and marine mammals due primarily to entanglement and ingestion is well documented (Gall and Thompson, 2015), the adverse effects of microplastics (particles $<5 \mathrm{~mm}$ in diameter) on marine wildlife is less well understood. In recent years, considerable research has been conducted using laboratory experiments to quantify the physical and chemical impacts of microplastics on marine organisms, including phyto- and zooplankton, corals, echinoderms, bivalves, and fish (Cole et al., 2013; Wright et al., 2013; Hall et al., 2015; Lönnstedt and Eklöv, 2016; Sjollema et al., 2016). These laboratory studies show that microplastics can impact an organism at many levels of biological organisation including changes in gene expression, inflammation, behaviour, growth and breeding success (for reviews, see Cole et al., 2013; Wright et al., 2013; GESAMP, 2015). Evidence of the trophic transfer of microplastics along the food chain has recently been

\footnotetext{
* Corresponding author.

E-mail address: concepcion.martinez@mu.ieo.es (C. Martínez-Gómez).
}

demonstrated from mussels to crabs (Farrell and Nelson, 2013) and from mesozooplankton to macrozooplankton (Setälä et al., 2014). It is well documented that early developmental stages of organisms exhibit a higher sensitivity to toxicants than other life stages, which may consequently adversely affect population levels (Beiras et al., 2012). There is previous evidence that pelagic larval stages, such as pluteus, trochophora and rotifer, are able to ingest and egest different sizes of plastic spheres (1.7, 2.7, 25, $32 \mu \mathrm{m}$ ) (Strathmann et al., 1972). The structures of marine communities depend, among other factors, on the ability of planktonic larvae to enter into adult populations, and there is the potential for the adverse impact of microplastics on eggs and embryos to threaten this. Therefore, developing embryos and marine larvae deserve special attention.

Polystyrene (PS) and polyethylene (PE) belong to the most commonly used plastics in the world and consequently to the most encountered plastics in marine environments (Andrady, 2011). PS is used in a variety of consumer and construction products, including food packaging and structures such as floating docks and buoys. HDPE is used in a wide variety of applications, such as plastic liquid food bottles and containers, plastic grocery sacks, housewares, sporting goods, piping, and plastic lumber (GESAMP, 2015). Many laboratory studies investigating the potential effects of microplastics use polymeric particles obtained from industry companies (Von Moos et al., 2012; Avio et al., 2015) or from commercial brands (Farrell and Nelson, 2013; Della Torre et al., 2014). Research on the particle toxicity of microplastics includes in vivo tests based on exposure to virgin microplastics, which are supposed to be free from any additives and/or residual monomers. Virgin fluorescent labelled plastic microspheres are frequently used as priority materials in laboratory exposure studies because they enable easy assessment of ingestion, bioaccumulation, tissue translocation and egestion processes (Besseling et al., 2013; Kaposi et al., 2014; Watts et al., 2014). However, the toxicity caused by co-contaminants leaching from the polymeric materials used in laboratory studies has received less attention and requires further research. Further, it has been found that unknown additives can leach from ingested microplastics (PVC) into the bodies of worms, reducing their feeding activity (Browne et al., 2013). The toxicological response 
resulting from the ingestion of microplastics may thus be due to cumulative or synergetic effects caused by inert particle and various leaching chemicals.

Our previous experience suggested that PS microspheres cause an effect on the pelagic fertilization and larval development of the sea urchin Paracentrotus lividus (Lamarck, 1816). In the present study we tested the working hypothesis that the observed and reported effects of virgin PS microspheres and HDPE fluff might be, at least in part, due to the leaching of co-contaminants. For this purpose, we investigated potential toxic effects on the pelagic fertilization and larval development of the sea urchin Paracentrotus lividus after exposure to virgin and experimentally aged PS and HDPE materials and their leachates.

\section{Material and methods}

\subsection{Model microplastics}

Commercial synthetic polymers of polystyrene (PS) microspheres (Fluoresbrite ${ }^{\mathrm{TM}}$ Polychromatic Red 6.0 Microspheres) and high density polyethylene (HPDE) fluff (Abifor 1300/20, Abifor Zürich, Switzerland) were used as proxies for microplastics in marine systems. The PS microspheres were purchased from Polysciences Europe GmbH (Germany): they had a diameter of $6 \mu \mathrm{m}$ and were uncharged. According to the technical specifications of the supplier, the PS microspheres are internally dyed using solvent swelling/dye entrapment. Further, the highly hydrophobic dyes (coumarin, fluorescein, rodhamine and phycoerythrin) remain trapped in the beads in aqueous environments, and some leaching of rodhamine may occur but only with aggressive washing. According to Abifor AG (Pers. comm. Marco Hilhorst, Abifor AG), the polymers used in this study were free of any additives. The HPDE fluff used was non-uniformly shaped grains ranging $>0-80 \mu \mathrm{m}$ in size (Gaussian distribution) and was free of additives. The grain size distribution according to EN-ISO 4610 standards is as follows: < $50 \mu \mathrm{m}=35-45 \%,<63 \mu \mathrm{m}=60-80 \%,<80 \mu \mathrm{m}=98-100 \%$ (Von Moos et al., 2012).

\subsection{Bioassays and test solutions}

About twenty mature sea urchin adults (Paracentrotus lividus) were sampled in March and April (reproductive period of the species) from the reference site Cala Reona (Murcia, SE Spain) and transported immediately to the laboratory. Gametes were obtained following methodology described in Saco-Álvarez et al. (2010) and Beiras et al. (2012), with minor modifications. Specimens were stimulated to spawn by osmotic-shock, injecting $2 \mathrm{~mL}$ of $0.5 \mathrm{M} \mathrm{KCl}$ through the peristomal membrane into the coelom. The organisms were allowed to spam for up to a maximum of $10 \mathrm{~min}$. Animals providing relatively little or dilute gametes were excluded for gamete sampling. Sperm was aspirated "dry" from the gonopore of selected males using a Pasteur pipette and samples were separately stored in beakers and held on ice $(<15 \mathrm{~min})$ until its posterior use. Females were inverted over a $200 \mathrm{~mL}$ beaker containing dilution FSW and left to release eggs. Prior to fertilization, gamete viability was assessed under a microscope (zoom x100) by placing by placing a subsample of gametes from each specimen in a drop of FSW. Eggs from each batch were checked for size and roundness, and they considered viable when more than $90 \%$ of the eggs were round, free of germinal vesicles and with a diameter ranging from 90 to $100 \mu \mathrm{m}$. Selected egg batches from three females were then filtered through a $150 \mu \mathrm{m}$ screen to remove pellets and pooled in a beaker containing $400 \mathrm{~mL}$ FSW. Eggs were washed three times by decantation, removing supernatant and adding dilution FSW and the final density determined. Sperm with highest motility and density (qualitatively assessed) was selected to conduct the bioassays. A standard sperm solution was prepared by adding about $500 \mu \mathrm{L}$ of the selected sperm to $24.5 \mathrm{~mL}$ of dilution FSW. Pre-trial testings were always conducted with the selected gametes in order to make sure the fecundation ratio was higher than $91 \%$ (Ghirardini et al., 2001). Sperm density was not calculated in our study as the control treatment in fertilization bioassay gives essential information regarding biological quality of the test organisms.

Exposure concentrations were chosen on the basis of trial experiments. All the test solutions for fertilization and embryotoxicity bioassay were prepared with filtered clean seawater (FSW) (offshore seawater from $150 \mathrm{~m}$ depth; $0.45 \mu \mathrm{m}$; HA Millipore; salinity $=38.0 \%$; $\mathrm{pH}=8.02$; dissolved oxygen $=8.1 \mathrm{mg} / \mathrm{L}$ ). Physicochemical parameters were recorded in all test chambers before and after each bioassay and adjusted when necessary to maintain optimum test conditions $(7.0<\mathrm{pH}<8.5 ; 35.0<$ salinity $<38.1$; dissolved oxygen $>2 \mathrm{mg} / \mathrm{L} ; \mathrm{H} 2 \mathrm{~S}<0.1 \mathrm{mg} / \mathrm{L} ; \mathrm{NH} 3<40 \mathrm{mg} / \mathrm{L}$ ) (SacoÁlvarez et al., 2010). All the fertilization and embryotoxicity bioassays were performed at a controlled temperature $\left(20^{\circ} \mathrm{C}\right)$.

\subsubsection{Fertilization bioassays}

Sea urchin eggs were mixed (stirring gently) with PS microspheres for $10 \mathrm{~min}$ in four test solutions (0 microspheres PS/mL FSW (control) and nominal concentrations of $10^{3}, 10^{4}$ and $10^{5} \mathrm{mi}-$ crospheres PS/mL FSW). Sixty $\mathrm{mL}$ of test solutions (2700 eggs $/ \mathrm{mL}$ FSW) were added to each test chamber (consisting of sterilized $100 \mathrm{~mL}$ flat-bottomed glass jars) before sperm addition. Then, a standard sperm solution was prepared as described above and $50 \mu \mathrm{L}$ of it was added to each test chamber (control and treatments). Solutions were stirred gently using a thin glass bar during $15 \mathrm{~min}$ and then the fecundation process was stopped by adding two drops of $40 \%$ buffered formalin in each test chamber. Three replicates were prepared per concentration (control and treatments). The fertilization rate (\%) in each test chamber was calculated by determining under the microscope the percentage of resulting zygotes (fertilized eggs identified by the fertilization membrane) in three subsamples of $20 \mu \mathrm{L}$; Total $n>300$ ). In addition, the normal zygotes obtained after exposing sea urchin gametes to PS microspheres were subsequently used to test potential late effects on embryo and larval development.

\subsubsection{Embryotoxicity bioassays}

The sea urchin embryotoxicity test (SET) was performed following the methodology described by Durán and Beiras (2010) and Beiras et al. (2012). Briefly, approximately 400 zygotes of Paracentrotus lividus were added straight after fertilization to the test chambers, being the developmental stage homogenous for all the treatments/replicates at the beginning of the test. Zygotes were added to each test chamber $(10 \mathrm{~mL})$ and incubated for $48 \mathrm{~h}$ at the control temperature $\left( \pm 20^{\circ} \mathrm{C}\right)$ and natural photoperiod. After that time, embryogenesis was stopped by adding two drops of $40 \%$ buffered formalin in each test chamber. Larvae were not fed during the bioassay. Five replicates were prepared per treatment. All samples were examined under optical and fluorescence microscopes after incubation (Olympus BX43; Software cellSens), and two toxicity parameters were calculated: percentage of pluteus larval abnormality ( $\mathrm{n}>150)$ (larvae were considered as morphologically normal when they exhibited four separated arms after $48 \mathrm{~h}$ incubation) and larval growth ( $\mathrm{n}>30$ ) (expressed as the percentage of net response or PNR). The PNR value is the response in the treatments (increase in length of the larvae) divided by the control, calculated according to Thain (1991).

The SETs included four experimental conditions: i) treated zygotes (zygotes obtained from exposed gametes from previous 
fertilization bioassay) incubated in FSW; ii) control zygotes incubated in untreated test solutions, which contain virgin PS microspheres or HDPE fluff; iii) control zygotes incubated in test solutions, which contain aged PS or aged HDPE fluff; and iv) control zygotes incubated in leachate test solutions of virgin PS or virgin HDPE polymeric particles. Untreated test solutions were aged for 30 days to natural ambient conditions of air, light and temperature. Test solutions of leachates were obtained from untreated solutions, which were sealed and stored for 30 days in darkness at ambient temperature and then filtered $\left(0.22 \mu \mathrm{m}\right.$ Whatman ${ }^{\odot}$ glass fibre, grade GF/F) before use. Three treatment nominal concentrations were used for each exposure experiment: $10^{3}, 10^{4}$ and $10^{5}$ microspheres PS/mL FSW and 0.005, 0.5 and $5 \mathrm{~g}$ HDPE fluff/L FSW concentrations. It was observed that test solutions underwent evaporation after 30 days of storage under ambient light, air, and temperature conditions. Consequently, for those solutions, the salinity was adjusted to $38 \%$ by adding filtered fresh water before conducting bioassays.

\subsection{Statistical analysis}

Statistical analyses were carried out using SPSS v.11.0 (IBM SPSS software/www.spsss.com). Data were transformed (arcsine of the square root) and tested for normality using Kolmogorov-Smirnov or Shapiro-Wilk tests (when the sampling size was $\leq 30$ ). However, the data presented in the figures and tables were not transformed. Homogeneity of variances was checked using Levene's test (Gilbert, 1987). Differences were checked by using parametric 1way ANOVA tests (Sokal and Rohlf, 1981) or non-parametric tests (Kruskal and Wallis, 1952), according to the nature of the data. If significant differences were found Dunett (Dunnett, 1995) or Dunnett T3 (Dunnett, 1980) post-hoc tests were applied for comparison against the control sample.

\section{Results and discussion}

The physicochemical characteristics of testing solutions during the fertilization bioassay (duration $10 \mathrm{~min}$ ) remained constant (temperature $=20{ }^{\circ} \mathrm{C}$; salinity $=38.0 \%$; $\mathrm{pH}=8.02$; dissolved oxygen $=8.1 \mathrm{mg} / \mathrm{L}$ ). Physicochemical parameters for the embryotoxicity bioassays were within the optimum valuesfor conducting the SET under all experimental conditions after incubation (Table S1).

\subsection{Effects of virgin PS microspheres on sea urchin fertilization}

Toxic effects on fertilization (ANOVA, post hoc Dunnett test; pvalue $<0.05$ ) were observed after the exposure of the sea urchin eggs to virgin PS microspheres (Fig. 1). The lowest fertilization rate was observed in eggs exposed to $10^{3}$ and $10^{4}$ PS microspheres $/ \mathrm{mL}$ FSW (56-58 \% success fertilization). Observation under optical and fluorescence microscopes showed that PS microspheres were not adsorbed to gamete/zygote membranes but rather were free in the test solutions. Zygotes obtained from each exposure treatment after fertilization bioassay were selected by visual inspection with a microscope, and immediately thereafter used for SET. When treated zygotes obtained in the fertilization bioassay were incubated in FSW, toxic effects on embryo and larval development were also found (Kruskal-Wallis test, p-value < 0.05) (Fig. 2). Larval abnormalities, including undeveloped embryos, collapsed embryo development at early stages, thickening and abnormal proliferation of the ectodermal membrane and reduced arm length, were observed. Unfortunately, no zygotes exposed to the lowest concentration during fertilization $\left(10^{3}\right.$ PS microspheres/mL FSW) were available due to inappropriate handling. Overall, the growth of

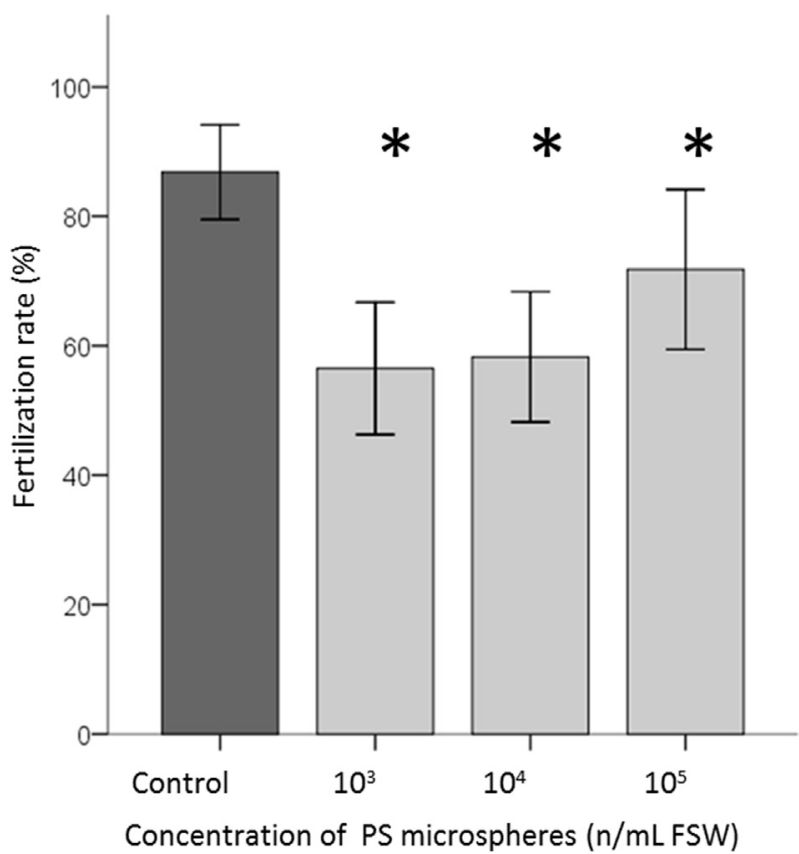

Fig. 1. Fertilization rates of Paracentrotus lividus eggs exposed to different concentrations of polystyrene microspheres (Mean \pm Standard Error of the mean; $n=3$ ). Asterisks indicate significant differences between the control and treatments (Dunnett test, p-value $<0.001$ ).

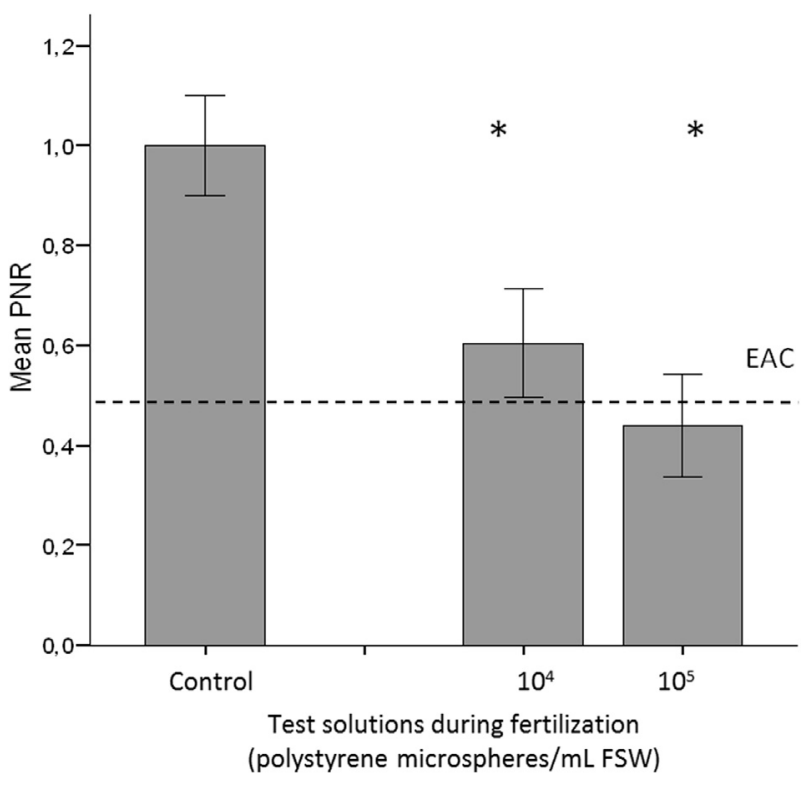

Fig. 2. Paracentrotus lividus larval growth quantified as the percentage net response (PNR) (Mean \pm Standard Error of the mean; $n=3$ ). Asterisks indicate significant differences relative to the control treatment (Mann-Whitney test, p-value $<0.05$ ). EAC: Environmental Assessment Criteria from Davies et al. (2012).

larvae from exposed gametes $\left(10^{4}\right.$ and $10^{5}$ PS microspheres/mL FSW) was significantly lower than that from controls after $48 \mathrm{~h}$ of incubation, and in a dose-dependent manner (Mann-Whitney test, p-value < 0.05) (Fig. 2). The decrease in larval size exceeded the environmental assessment criterion value (mean PNR $>0.5$ ), which is indicative of significant harm to the species (Davies et al., 2012). Overall, the results suggest that the sublethal toxic effects were already caused at initial exposure (during fertilization) and 
manifested later during embryo/larval development.

\subsection{Effects of PS microspheres and its leachates on sea urchin embryo development}

Exposure of the sea urchin zygotes to untreated and aged PS microspheres as well as to leachates of virgin PS microspheres also resulted in toxic effects on embryo development (ANOVA 1-way; Dunnett post hoc test; p-value $<0.05$ ) and larval growth (Kruskal Wallis; Dunnett T3 post hoc test; p-value $<0.05$ ). Toxic effects exceeding the environmental assessment criteria (\% abnormality $>$ $50 \%$ ) (Davies et al., 2012) were only found on the zygotes exposed to leachates from the lowest concentration $\left(10^{3}\right.$ microspheres de $\mathrm{PS} / \mathrm{mL}$ FSW), with a $100 \%$ prevalence of pre-embryo in the gastrula stage being found (Table 1; Fig. 3; Fig. 4). In spite of the fact that significant differences between control and PS exposed larvae were found in most of the samples (with the exception of the sample with highest concentration of untreated PS microspheres), embryotoxicity did not follow a dose-dependent pattern (Fig. 5). However, visual inspection indicated that pluteus larvae ingested PS microspheres from test solutions (Fig. 6) in a dose-dependent manner at the time of the SET completion (48 h). This finding suggests that observed embryo development abnormalities were not directly related to the presence of PS microspheres within the gastric cavity of the larvae. Aggregates $(300-500 \mu \mathrm{m})$ of PS microspheres were observed in the testing solutions with the highest concentrations (Fig. S1), which can limit their potential leaching.

\subsection{Effects of HDPE fluff and its leachates on sea urchin embryo development}

Sea urchin zygotes exposed to untreated and aged HDPE fluff as well as to leachates of virgin HDPE fluff also resulted in toxic effects on embryo development (ANOVA 1-way; Dunnett post hoc test; pvalue $<0.05$ ) and larval growth (Kruskal Wallis; Dunnett T3 post hoc test; p-value $<0.05$ ). As for PS microspheres, toxic effects exceeding the environmental assessment criteria (\% abnormality $>$ $50 \%$ ) (Davies et al., 2012) were only found on the zygotes exposed to leachates from the lowest concentrations (0.005 g HDPE/L), where most larvae were in pre-pluteus stage (ANOVA 1-way; Dunnett post hoc test; p-value < 0.05) (Fig. 3, Table 1). Similar toxicity results of abnormalities (from $20 \%$ to $40 \%$; PNR from 0.87 to 0.67 ) were found in all the aged test solution concentrations (Fig. 5, Table 1). With regard to the exposure to untreated solutions, the highest percentages of larval development abnormalities were found at the highest concentration (5 g HDPE / L FSW) (Fig. 5, Table 1). Similarly to the observed results with PS microspheres, the number of larvae with HDPE fluff within the gastric cavity (from test solutions containing untreated or aged PS microspheres) increased in a concentration-dependent manner.

\subsection{Physical and chemical toxicity of microplastics}

The toxicological effects resulting from ingestion and exposure to microplastics may be a combination of physical and chemical toxicity (Browne et al., 2013; Teuten et al., 2009; GESAMP, 2015). We found that the exposure of sea urchin gametes and zygotes to virgin and aged PS and HPDE microplastics as well as their leachates caused toxic effects on the fecundation rate and embryonic development. The marked difference in toxicity on embryo development between the virgin and aged microplastics test solutions and the virgin microplastic leachate test solutions suggests that some leached compounds were volatilized or photodegraded rapidly. Furthermore, the leachates of these virgin materials were more embryotoxic than the virgin and aged materials themselves. This can be due to the higher bioavailability of leached contaminants in a solution without suspended material (sorption-desorption equilibrium not present). As mentioned in the methodology, there are no technical specifications from the supplier on the use of additives in any of the microplastics used in our study. According to the specifications, it is unlikely that fluorescent dyes could have leached from the PS microspheres into seawater. These findings suggest that the observed toxicity is likely caused either by the migration of toxic residual or unreacted quantities of styrene/ ethylene monomers, as well as also by unknown toxic chemicals used in production and process additives (such as antioxidant) from the virgin PS microspheres and HDPE fluff. This interpretation of our results is supported by the finding that styrene monomers have been detected in leachates from the same commercial stock of PS microspheres (FluoresbriteTM Polychromatic Red 6.0 Microspheres) that was used in our study (Björnsdotter, 2015). Styrene monomers from fluorescent PS microsphere solutions $\left(6 \cdot 10^{5} \mathrm{mi}\right.$ crospheres/mL seawater) were analysed with GC-MS, reaching a concentration of $0.17 \mu \mathrm{g} \mathrm{mL}^{-1}$ within $24 \mathrm{~h}$ (Björnsdotter, 2015). The author suggests that using a concentration equal to or lower than $6 \times 10^{5}$ PS in particle toxicity studies would likely lead to a lower toxicity caused by a leached styrene monomer in the solutions. However, we found that leachate solutions obtained from the

Table 1

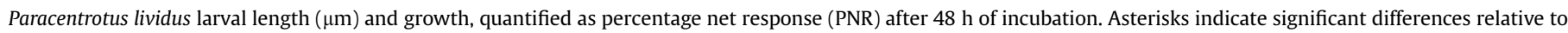
control treatment (Mann-Whitney test, $\mathrm{p}$-value $<0.05$ ). SE = Standard error of the mean; PS= Polystyrene; HDPE $=$ High density polyethylene.

\begin{tabular}{|c|c|c|c|c|c|}
\hline Concentration (microspheres PS/mL sea water) & Length $\pm \mathrm{SE}(\mu \mathrm{m})$ & $\mathrm{PNR} \pm \mathrm{SE}$ & Concentration (gr HDPE/L sea water) & Length $\pm \mathrm{SE}(\mu \mathrm{m})$ & $\mathrm{PNR} \pm \mathrm{SE}$ \\
\hline \multicolumn{3}{|l|}{ Exposure to virgin PS microspheres } & \multicolumn{3}{|l|}{ Exposure to virgin HDPE fluff } \\
\hline $\begin{array}{l}\text { Control } \\
10^{3} \\
10^{4} \\
10^{5}\end{array}$ & $\begin{array}{l}316 \pm 4 \\
269 \pm 5 \\
272 \pm 6 \\
289 \pm 6\end{array}$ & $\begin{array}{l}1.00 \pm 0.00 \\
0.77 \pm 0.02 \\
0.78 \pm 0.02 \\
0.82 \pm 0.02\end{array}$ & $\begin{array}{l}\text { Control } \\
0.005 \\
0.5 \\
5\end{array}$ & $\begin{array}{l}288 \pm 4 \\
261 \pm 4 \\
264 \pm 5 \\
241 \pm 0\end{array}$ & $\begin{array}{l}1.00 \pm 0.00 \\
0.59 \pm 0.01 \\
0.60 \pm 0.02 \\
0.52 \pm 0.02\end{array}$ \\
\hline \multicolumn{3}{|l|}{ Exposure to aged PS microspheres } & \multicolumn{3}{|l|}{ Exposure to aged HDPE fluff } \\
\hline $\begin{array}{l}\text { Control } \\
10^{3} \\
10^{4} \\
10^{5}\end{array}$ & $\begin{array}{l}424 \pm 6 \\
302 \pm 5 \\
355 \pm 7 \\
336 \pm 7\end{array}$ & $\begin{array}{l}1.00 \pm 0.00 \\
0.63 \pm 0.01 \\
0.78 \pm 0.02 \\
0.73 \pm 0.02\end{array}$ & $\begin{array}{l}\text { Control } \\
0.005 \\
0.5 \\
5\end{array}$ & $\begin{array}{l}453 \pm 5 \\
332 \pm 6 \\
417 \pm 7 \\
354 \pm 4\end{array}$ & $\begin{array}{l}1.00 \pm 0.00 \\
0.67 \pm 0.02 \\
0.87 \pm 0.02 \\
0.73 \pm 0.01\end{array}$ \\
\hline \multicolumn{3}{|l|}{ Exposure to leachates of virgin PS microspheres } & \multicolumn{3}{|l|}{ Exposure to leachates of virgin HDPE fluff } \\
\hline $\begin{array}{l}\text { Control } \\
10^{3} \\
10^{4} \\
10^{5}\end{array}$ & $\begin{array}{l}459 \pm 5 \\
124 \pm 2 \\
344 \pm 5 \\
331 \pm 6\end{array}$ & $\begin{array}{l}1.00 \pm 0.00 \\
0.09 \pm 0.00 \\
0.69 \pm 0.01 \\
0.65 \pm 0.01\end{array}$ & $\begin{array}{l}\text { Control } \\
0.005 \\
0.5 \\
5\end{array}$ & $\begin{array}{l}436 \pm 6 \\
280 \pm 6 \\
408 \pm 6 \\
435 \pm 34\end{array}$ & $\begin{array}{l}1.00 \pm 0.00 \\
0.55 \pm 0.02 \\
0.89 \pm 0.02 \\
0.70 \pm 0.03\end{array}$ \\
\hline
\end{tabular}




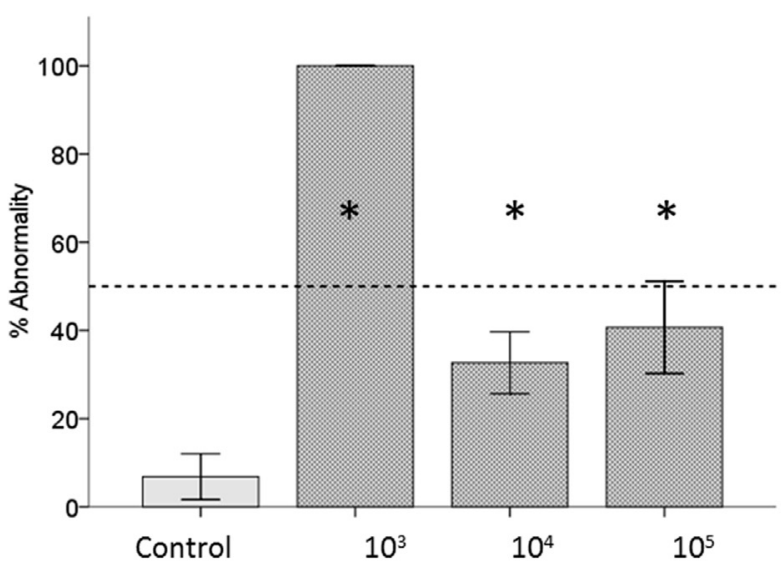

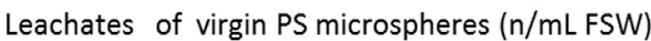

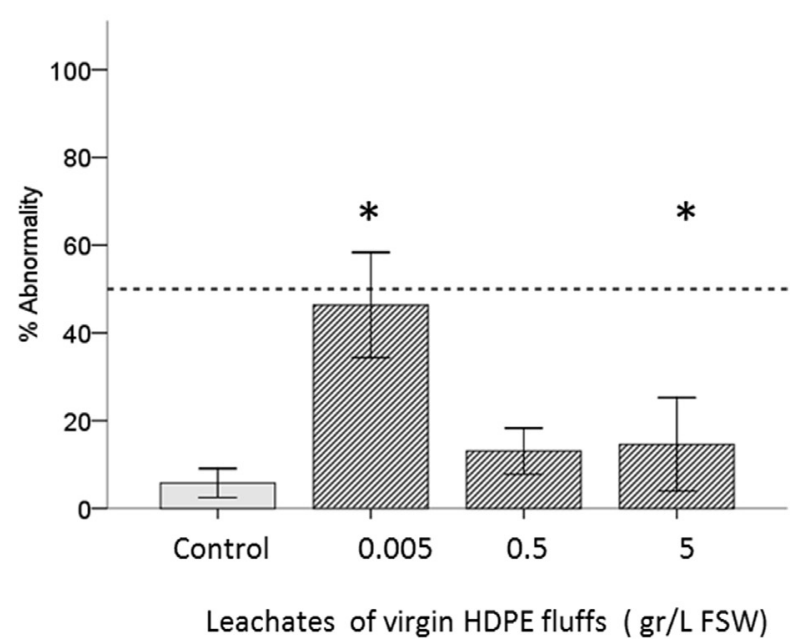

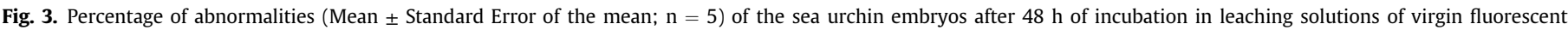

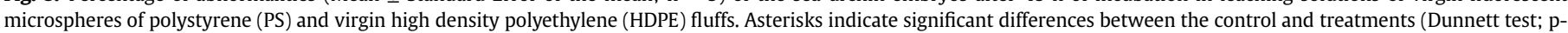
value $<0.05$ ). Dashed lines indicate the environmental assessment criteria proposed for this species (Davies et al., 2012).

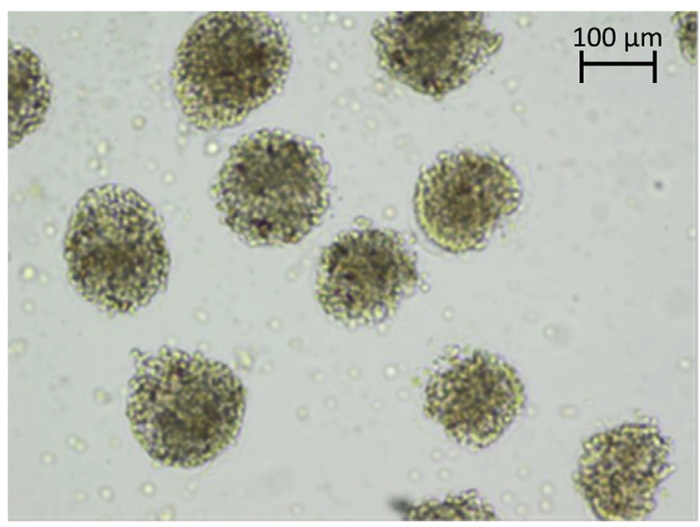

Fig. 4. Example of sea urchin embryos in gastrula stage after $48 \mathrm{~h}$ of incubation in a leaching solution of $10^{3}$ virgin polystyrene (PS) microspheres/mL filtered seawater.

lowest concentration of both polymeric materials caused the highest embryotoxicity. These findings can be explained by microplastic aggregation processes, which were observed in the untreated PS microspheres and HDPE fluff solutions in a dosedependent manner (Figs. S1 and S2). Larger MP aggregates, because of lower surface areas, will have lower water contact surface than the smaller ones with lower numbers of free MP particles in the solutions. The highest rate of migration and leaching of compounds from the MPs in the untreated solutions with the lowest MP concentrations could possibly explain the significantly highest chemical toxicity observed in the MP leachates from the lowest concentrations. Reports on the toxicity of styrene to aquatic invertebrates are usually limited to acute studies under open and static conditions. The threshold for acute effects falls in the range of 50-100 $\mu \mathrm{g} \mathrm{mL}^{-1}$ for many organisms (Canadian Environment, 2003), although it has been demonstrated that styrene causes mortality in the snail Ilyanassa. obsoleta at concentrations as low as $0.05 \mu \mathrm{g} \mathrm{mL} \mathrm{mL}^{-1}$ (Romano, 2007). On the other hand, Björnsdotter (2015) also found measurable concentrations of 6 aliphatic hydrocarbons (C14, C16, C18, C20, and C22) in leachates of the same HDPE fluff stock that we used in our study (Abifor 1300/20, Abifor Zürich, Switzerland). Aliphatic hydrocarbons were detected in leaching solutions of HDPE fluff in artificial seawater $(20 \mathrm{~g} / \mathrm{L})$, which might cause a chronic toxic response in aquatic organisms (Björnsdotter, 2015). Our results are generally consistent with recent investigations into chemical toxicity of macroplastic leachates to invertebrates. Exposure to virgin plastic pellets has shown to cause toxic effects on the embryonic development of sea-urchin (Nobre et al., 2015) and mussels (Silva et al., 2016). Bejgarn et al. (2015) found that leachates from plastic products caused acute toxicity to the marine copepod Nitocra spinipes, although toxic leachates from cups (PS) and garbage bags (HDPE) were not found. Leachates from seven commercial plastics, including PS and HDPE macroplastics $(1 \times 1 \mathrm{~cm}$ sections) significantly increased barnacle nauplii (Amphibalanus amphitrite) mortality at the highest tested concentrations $\left(0.10\right.$ and $\left.0.50 \mathrm{~m}^{2} / \mathrm{L}\right)$ and inhibited the settlement on glass with plastic leachates (Li et al., 2016). PS microspheres used in our study caused sea urchin embryotoxicity to a lower nominal exposure surface $\left(0.0001-0.01 \mathrm{~m}^{2} / \mathrm{L}\right)$ than those used by Li et al. (2016). Despite differences in the methodology and species, our results support the observations of Li et al. (2016), who suggest that toxicity of plastic leachates is life-stage dependent.

On the other hand, PS microspheres did not adhere to sea urchin gamete/zygote membranes but rather were free in the test solutions, suggesting again that the deleterious effects observed in our study were more likely caused by chemical toxicity than by physical harm. The ingestion of PS microspheres and HDPE fluff in the larvae gastric cavity was observed in our study. Whereas the number of larvae with MPs in the gastric cavity occurred consistently in a dose-dependent manner, the larvae abnormality rate was overall similar between treatments ( $\mathrm{p}$-value $>0.05$ ). Retention, distribution and toxicity of microplastics can be diverse and depend on the size, physicochemical characteristics and host species (Wright et al., 2013). Consistent with our results, several studies have reported that ingestion of microplastics by marine invertebrates have no significant deleterious effects on some adult invertebrate species such as sand hoppers and isopods (Ugolini et al., 2013; Hämer et al., 2014), and that they pose a limited threat to sea urchins, at least during its planctotrophic larval stage (Kaposi et al., 2014). Ingestion of $10-45 \mu \mathrm{m}$ polyethylene (PE) microspheres by the larvae of the sea urchin Tripnesteus gratilla did not have significant effects on survival and larval growth, and the larvae were able to egest microspheres from their stomach within hours of ingestion (Kaposi et al., 2014). Similar observations were found in the larvae of the sea urchin Paracentrotus lividus exposed to negatively charged 

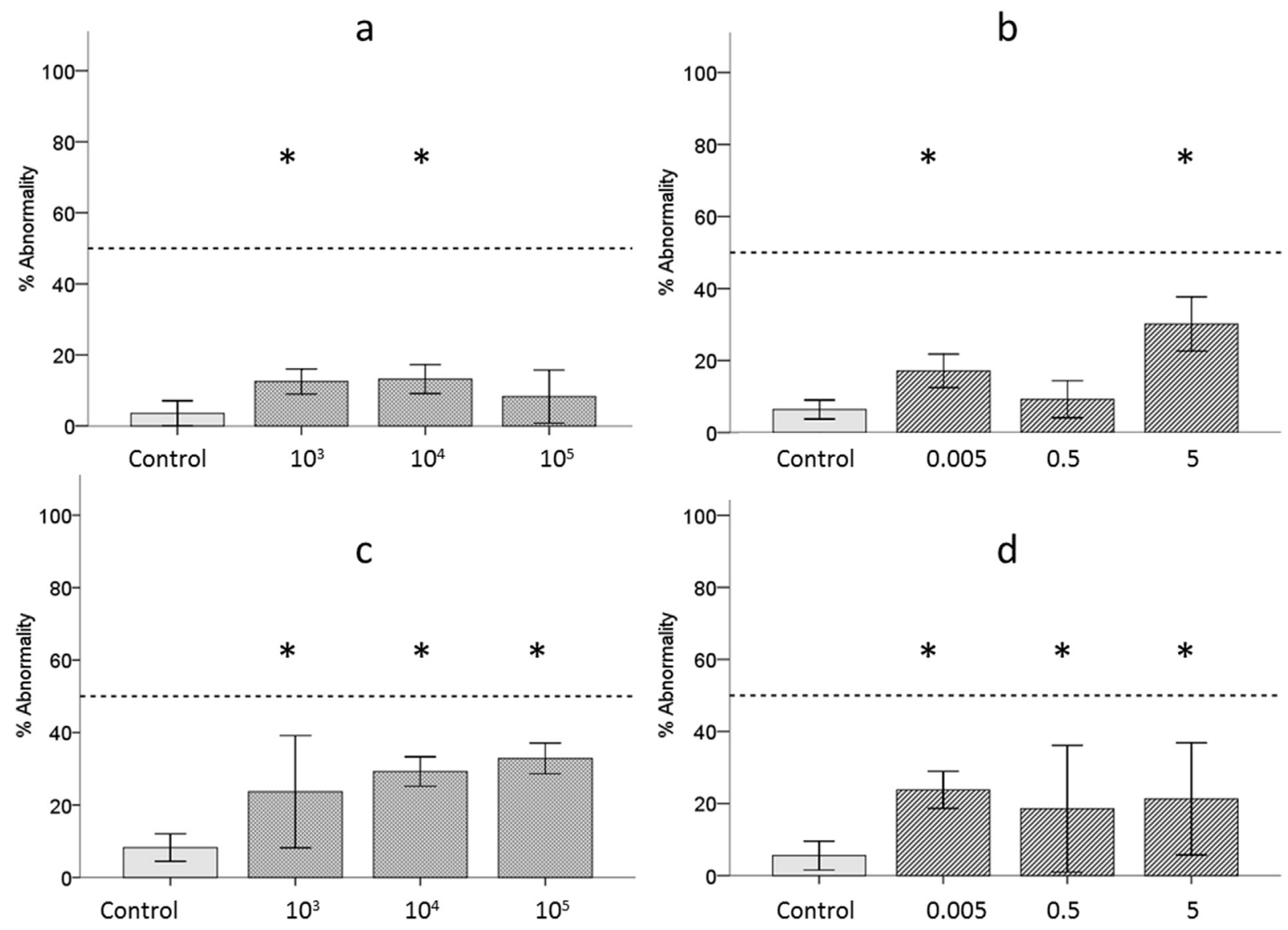

Concentration of PS microspheres $(\mathrm{n} / \mathrm{mL}$ FSW)

Concentration of HDPE fluff (gr/LFSW)

Fig. 5. Percentage of abnormalities (Mean \pm Standard Error of the mean; $n=5$ ) of the sea urchin embryos after $48 \mathrm{~h}$ of incubation in testing solutions of virgin fluorescent microspheres of polystyrene (PS) (a), virgin high density polyethylene (HDPE) fluffs (b), aged fluorescent microspheres of PS (c) and aged HDPE fluffs (d). Asterisks indicate significant differences between the control and treatments (Dunnett test; p-value $<0.05$ ). Dashed lines indicate the environmental assessment criteria proposed for this species (Davies et al., 2012).

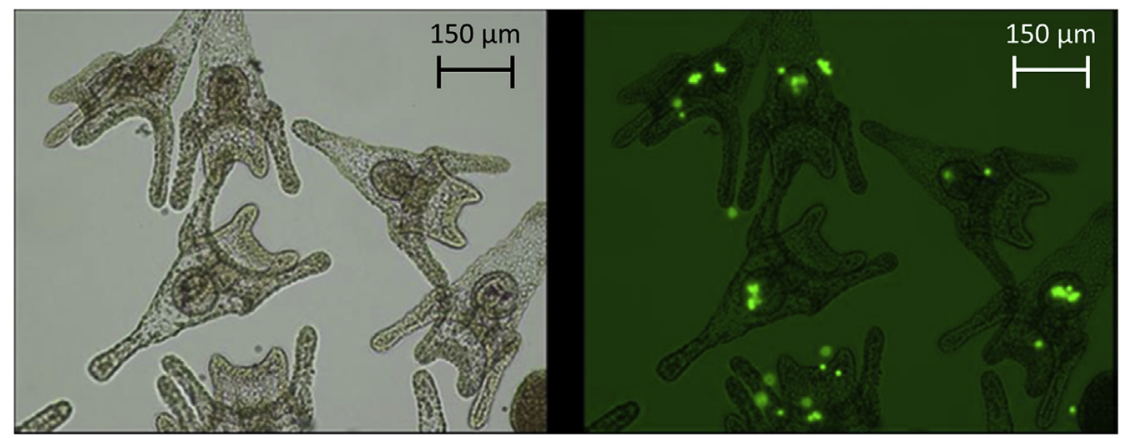

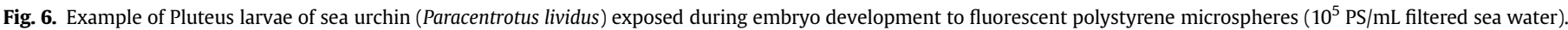
Samples examined under optical (left side) and fluorescence (right side) microscope after incubation (zoom x400; Olympus BX43; Software cellSens).

carboxylated polystyrene (PS-COOH) aggregates (> $1000 \mathrm{~nm}$ ) (Della Torre et al., 2014). However, exposure to positively charged amine modified polystyrene ( $\left.\mathrm{PS}-\mathrm{NH}_{2}\right)$ aggregates $(<100 \mathrm{~nm})$ caused embryotoxicity in larvae of this species with no clear incorporation of PS- $\mathrm{NH}_{2}$ in embryos (Della Torre et al., 2014), a finding that is congruent with the leachate test solution toxicity results observed in our study. These authors exposed the sea urchin larvae at varying concentrations $(1,10,100$ and $300 \mathrm{PE}$
microspheres/mL seawater) in high-capacity open tanks for 5 days, and consequently PE microspheres were subjected to aging processes (Kaposi et al., 2014), supporting our results of the absence of physical effects related with the ingestion of MP into the gastric cavity. Therefore, it seems likely that Paracentrotus lividus larvae would eject PS microspheres after a period of several days, as in the case of Tripneustes gratilla, although longer bioassays should be performed to demonstrate it. 
The greatest proportion of small MP particles $(<80 \mu \mathrm{m})$ have been found in the $10-20 \mu \mathrm{m}$ size fraction $\left(0.0005 \mathrm{~mL}^{-1}\right)$, with high abundances observed in coastal waters and particularly in the upper $55 \mathrm{~m}$. This is likely as a consequence of the pycnocline barrier (Enders et al., 2015). As far as we know, the highest concentrations of small MPs recorded in the marine environment $(<80 \mu \mathrm{m} ; 0.1$ milky-white microspheres $\cdot \mathrm{mL}^{-1}$ ) were reported in a Swedish industrial harbour (Norén, 2007), and were four orders of magnitude lower than the lowest concentration used in our study $(6 \mu \mathrm{m}$; 100 PS microspheres $\cdot \mathrm{mL}^{-1}$ ). However, it has been found that up to 100000 times higher concentrations of small MPs (fibres) are retained on an $80 \mu \mathrm{m}$ mesh compared to a $450 \mu \mathrm{m}$ mesh (Norén, 2007). Detection methods for small microplastics are in an early stage of development (Solomon and Palanisami, 2016) and to date the concentrations of MPs in oceanic or coastal waters with a size similar to those used in our study are largely unknown.

The marked difference in toxicity between virgin/aged MPs and virgin MP leachates on embryo development suggests that some leached compounds from virgin MPs were volatilized or photodegraded rapidly. Our observations suggest that particle aggregation can be expected if MPs are introduced into marine waters at the concentrations used in our study. It is plausible that organic matter fouling and subsequent hetero-aggregation with suspended solids, algae or detritus, marine snow, etc. will cause settling of MPs in the pycnocline and sediments (Enders et al., 2015; Long et al., 2015). It has been suggested that the presence of MPs in the marine waters represents a limited threat to the larvae of marine invertebrate organisms, at least during its planctotrophic larval stage (Kaposi et al., 2014). Our data suggest that pelagic invertebrate eggs/zygotes and embryos exposed to supposedly virgin microplastics in confined environments may experience lethal toxic effects to leached chemicals from plastic materials. In our study, the effect of the level of chemical toxicity on the sea urchin embryonic development passed the environmental assessment criteria at leachates solutions with concentrations of $10^{3} \mathrm{PS}$ microspheres/mL seawater and at 0.005 gr HDPE fluff/L sea water (Beiras et al., 2012; Davies et al., 2012). The toxicity caused by leaching substances during the dissociation of microplastic aggregates into the marine environment may be of concern and requires further research.

\section{Conclusions}

The chemical toxicity of virgin fluorescent polystyrene microspheres $(\varnothing 6 \mu \mathrm{m})$ and virgin high density polyethylene fluff ( $~$ $0-80 \mu \mathrm{m}$ ) on sea urchin gametes and embryos has been demonstrated. The leachates of these two polymeric materials caused a higher toxicity to sea urchin embryos than virgin and aged materials themselves. The presence of suspended materials (MPs or others) can reduce the total fraction available and their toxicity. Virgin microplastics may leach unknown chemicals, e.g., additives or residual and toxic monomers, which appear to be mainly responsible for the observed sea urchin embryotoxicity. Virgin micro- and nanoplastics are frequently used as priority model materials in aquatic toxicity laboratory studies. Our results highlight the necessity to wash or weather the microplastics before toxicity testing to obtain clean and chemically inert polymeric materials to allow a more realistic extrapolation to field conditions.

\section{Acknowledgments}

This work was supported by the Spanish Ministry of Economy and Competitiveness (IMPACTA Project - CTM2013-48194-C3-1-R) and by the CleanSea project, part of the European Union Seventh Framework Programme (FP7/2007-2013), under grant agreement $n^{\circ}$ 308370. The contents of this publication are the sole responsibility of the CleanSea Project and should in no way be regarded as reflecting the views of the European Union. Dr. Angela Köhler is acknowledged for providing the HDPE fluff.

\section{Appendix A. Supplementary data}

Supplementary data related to this article can be found at http:// dx.doi.org/10.1016/j.marenvres.2017.06.016.

\section{References}

Ugolini, A., Ungherese, G., Ciofini, M., Lapucci, A., Camaiti, M., 2013. Microplastic debris in sandhoppers. Estuar. Coast. Shelf Sci. 129, 19-22.

Andrady, A.L., 2011. Microplastics in the marine environment. Mar. Pollut. Bull. 62 (8), 1596-1605.

Avio, C.G., Gorbi, S., Milan, M., Benedetti, M., Fattorini, D., d'Errico, G., Pauletto, M., Bargelloni, L., Regoli, F., 2015. Pollutants bioavailability and toxicological risk from microplastics to marine mussels. Environ. Pollut. 198, 211-222.

Beiras, R., Durán, I., Bellas, J., Sánchez-Marín, P., 2012. Biological effects of contaminants: Paracentrotus lividus sea urchin embryo test with marine sediment elutriates. International Council for the Exploration of the Sea, Techn. Environ. Mar. Sci. 51, 1-13.

Bejgarn, S., MacLeod, M., Bogdal, C., Breitholtz, M., 2015. Toxicity of leachate from weathering plastics: an exploratory screening study with Nitocra spinipes. Chemosphere 132, 114-119. http://dx.doi.org/10.1016/ j.chemosphere.2015.03.010.

Besseling, E., Wegner, A., Foekema, E.M., Van Den Heuvel-Greve, M.J., Koelmans, A.A., 2013. Effects of microplastic on fitness and PCB bioaccumulation by the lugworm Arenicola marina (L.). Environ. Sci. Technol. 47 (1), 593-600. http://dx.doi.org/10.1021/es302763x.

Björnsdotter, M., 2015. Leaching of Residual Monomers, Oligomers and Additives from Polyethylene, Polypropylene, Polyvinylchloride, High-density Polyethylene and Polystyrene Virgin Plastics. Bachelor thesis,. School of Science and Technology, Örebro University, Sweden, 18 pp.

Browne, M.A., Niven, S.J., Galloway, T.S., Rowland, S.J., Thompson, R.C., 2013. Microplastic moves pollutants and additives to worms, reducing functions linked to health and biodiversity. Curr. Biol. 23, 2388-2392.

Cole, M., Lindeque, P., Fileman, E., Halsband, C., Goodhead, R., Moger, J., Galloway, T.S., 2013. Microplastic ingestion by zooplankton. Environ. Sci. Technol. 47 (12), 6646-6655.

Davies, I.M., Gubbins, M., Hylland, K., Thain, J., Maes, T., Martínez-Gómez, C., Giltrap, M., Burgeot, T., Wosniok, W., Lang, T., Vethaak, D., 2012. Technical Annex 30: Assessment Criteria for Biological Effects Measurements. In: Integrated Monitoring of Chemicals and Their Effects, pp. 209-212. International Council for the Exploration of the Sea, ICES Cooperative Research Report 315.

Della Torre, C., Bergami, E., Salvati, A., Faleri, C., Cirino, P., Dawson, K.A., Corsi, I. 2014. Accumulation and embryotoxicity of polystyrene nanoparticles at early stage of development of sea urchin embryos Paracentrotus lividus. Environm. Sci. Technol. 48 (20), 12302-12311.

Dunnett, C.W., 1980. Pairwise multiple comparisons in the unequal variance case. J. Amer. Stat. Assoc. 75 (372), 796-800.

Dunnett, C.W., 1995. A multiple comparison procedure for comparing several treatments with a control. J. Amer. Stat. Assoc. 50, 1096-1121.

Durán, I., Beiras, R., 2010. Assessment criteria for using the sea-urchin embryo test with sediment elutriates as a tool to classify the ecotoxicological status of marine water bodies. Environ. Toxicol. Chem. 29 (5), 1192-1198.

Enders, K., Lenz, R., Stedmon, C.A., Nielsen, T.G., 2015. Abundance, size and polymer composition of marine microplastics $\geq 10 \mu \mathrm{m}$ in the Atlantic Ocean and their modelled vertical distribution. Mar. Pollut. Bull. 100 (1), 70-81.

Canadian Environment, 2003. Follow-up Report on a PSL1 Substance for Which There Was Insufficient Information to Conclude whether the Substance Constitutes a Danger to the Environment. Styrene, 15 pp.. Last accessed 17/11/2016. http://www.ec.gc.ca/ese-ees/default.asp?lang=En\&n=35DA297C-1.

Farrell, P., Nelson, K., 2013. Trophic level transfer of microplastic: Mytilus edulis (L.) to Carcinus maenas (L.). Environ. Pollut. 177, 1-3.

Gall, S.C., Thompson, R.C., 2015. The impact of debris on marine life. Mar. Pollut. Bull. 92 (1), 170-179.

Galloway, T.S., Lewis, C.N., 2016. Marine microplastics spell big problems for future generations. Proc. Nat. Acad. Sci. 113 (9), 2331-2333.

GESAMP, 2015. Sources, fate and effects of microplastics in the marine environment: a global assessment. In: Kershaw, P.J. (Ed.), (IMO/FAO/UNESCOIOC/ UNIDO/WMO/IAEA/UN/UNDP Joint Group of Experts on the Scientific Aspects of Marine Environmental Protection). Rep. Stud. GESAMP No. 90, 96 pp.

Ghirardini, A.V., Novelli, A.A., Likar, B., Pojana, G., Ghetti, P.F, Marcomini, A, 2001 Sperm cell toxicity test using sea urchin Paracentrotus lividus Lamarck (Echinodermata: echinoidea): sensitivity and discriminatory ability toward anionic and nonionic surfactants. Environ. Toxicol. Chem. 20 (3), 644-651.

Gilbert, O.R., 1987. Statistical Methods for Environmental Pollution Monitoring, first ed. New York.

Hall, N.M., Berry, K.L.E., Rintoul, L., Hoogenboom, M.O., 2015. Microplastic ingestion 
by scleractinian corals. Mar. Biol. 162 (3), 725-732.

Hämer, J., Gutow, L., Köhler, A., Saborowski, R., 2014. Fate of microplastics in the marine isopod Idotea emarginata. Environ. Sci. Technol. 48 (22), 13451-13458.

Kaposi, K.L., Mos, B., Kelaher, B.P., Dworjanyn, S.A., 2014. Ingestion of microplastic has limited impact on a marine larva. Environ. Sci. Technol. 48 (3), 1638-1645.

Kruskal, W.H., Wallis, W.A., 1952. Use of ranks in one-criterion variance analysis. J. Amer. Stat. Assoc. 47 (260), 583-621.

Li, H.X., Getzinger, G.J., Ferguson, P.L., Orihuela, B., Zhu, M., Rittschof, D., 2016. Effects of toxic leachate from commercial plastics on larval survival and settlement of the barnacle Amphibalanus amphitrite. Environ. Sci. Technol. 50 (2), 924-931. http://dx.doi.org/10.1021/acs.est.5b02781.

Long, M., Moriceau, B., Gallinari, M., Lambert, C., Huvet, A., Raffray, J., Soudant, P., 2015. Interactions between microplastics and phytoplankton aggregates: impact on their respective fates. Mar. Chem. 175, 39-46.

Lönnstedt, O.M., Eklöv, P., 2016. Environmentally relevant concentrations of microplastic particles influence larval fish ecology. Science 352 (6290), 1213-1216.

Mato, Y., Isobe, T., Takada, H., Kanehiro, H., Ohtake, C., Kaminuma, T., 2001. Plastic resin pellets as a transport medium for toxic chemicals in the marine environment. Environ. Sci.Technol 35 (2), 318-324.

Nobre, C.R., Santana, M.F.M., Maluf, A., Cortez, F.S., Cesar, A., Pereira, C.D.S., Turra, A., 2015. Assessment of microplastic toxicity to embryonic development of the sea urchin Lytechinus variegatus (Echinodermata: echinoidea). Mar. Pollut. Bull. 92 (1), 99-104

Norén, F., 2007. Small Plastic Particles in Coastal Swedish Waters. Tech. Rep. 0, KIMO. https://www.researchgate.net/publication/284312290_Small_plastic particles_in_Coastal_Swedishwaters. Last access 15/02/2017.

Romano, J.A., 2007. Acute Toxicity and Sub-lethal Effects of Non-Point Source Pollutants on Invertebrates by University Program in Integrated Toxicology Nicholas School of the Environment and Earth Sciences. Duke University, Durham NC, USA. Thesis dissertation. $171 \mathrm{pp}$.

Saco-Álvarez, L., Durán, I., Lorenzo, J.I., Beiras, R., 2010. Methodological basis for the optimization of a marine sea-urchin embryo test (SET) for the ecological assessment of coastal water quality. Ecotox. Environ. Safe 73 (4), 491-499.
Setälä, O., Fleming-Lehtinen, V., Lehtiniemi, M., 2014. Ingestion and transfer of microplastics in the planktonic food web. Environ. Pollut. 185, 77-83.

Silva, P.P.G., Nobre, C.R., Resaffe, P., Pereira, C.D.S., Gusmão, F., 2016. Leachate from microplastics impairs larval development in brown mussels. Water Res. 106 364-370. http://dx.doi.org/10.1016/j.watres.2016.10.016.

Sjollema, S.B., Redondo-Hasselerharm, P., Leslie, H.A., Kraak, M.H., Vethaak, A.D. 2016. Do plastic particles affect microalgal photosynthesis and growth? Aquat. Toxicol. 170, 259-261.

Sokal, R.R., Rohlf, F.J., 1981. The Principles and Practice of Statistics in Biological Research. W. H. Freeman, San Francisco, CA, 785pp.

Solomon, O.O., Palanisami, T., 2016. Microplastics in the marine environment: current status, assessment methodologies, impacts and solutions. J. Pollut. Eff. Cont. 1-13.

Strathmann, R.R., Jahn, T.L., Fonseca, J.R., 1972. Suspension feeding by marine invertebrate larvae: clearance of particles by ciliated bands of a rotifer, pluteus, and trochophore. Biol. Bull. 142 (3), 505-519.

Teuten, E.L., Saquing, J.M., Knappe, D.R.U., Barlaz, M.A., Jonsson, S., Björn, A., Rowland, S.J., Thompson, R.C., Galloway, T.S., Yamashita, R., Ochi, D., Watanuki, Y., Moore, C., Viet, P.H., Tana, T.S., Prudente, M., Boonyatumanond, R. Zakaria, M.P., Akkhavong, K., Ogata, Y., Hirai, H., Iwasa, S., Mizukawa, K. Hagino, Y., Imamura, A., Saha, M., Takada, H., 2009. Transport and release of chemicals from plastics to the environment and to wildlife. Philos. Trans. R. Soc. Biol. Sci. 364, 2027-2045.

Thain, J., 1991. Biological effects of contaminants: oyster embryo bioassay. International Council for the Exploration of the Sea, Techn. Environ. Mar. Sci. 11.

Von Moos, N., Burkhardt-Holm, P., Köhler, A., 2012. Uptake and effects of microplastics on cells and tissue of the blue mussel Mytilus edulis L. after an experimental exposure. Environ. Sci. Technol. 46 (20), 11327-11335.

Watts, A.J., Lewis, C., Goodhead, R.M., Beckett, S.J., Moger, J., Tyler, C.R. Galloway, T.S., 2014. Uptake and retention of microplastics by the shore crab Carcinus maenas. Environ. Sci. Technol. 48 (15), 8823-8830.

Wright, S.L., Thompson, R.C., Galloway, T.S., 2013. The physical impacts of microplastics on marine organisms: a review. Environ. Pollut. 178, 483-492. 